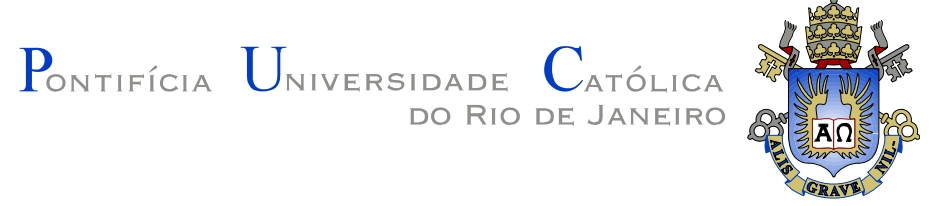

Andréia Clapp Salvador

\title{
Ação Afirmativa no Ensino Superior: Estudo da Política de Inserção de Alunos Pobres e Negros na PUC-Rio
}

Tese apresentada ao Programa de Pós-Graduação em Serviço Social do Departamento de Serviço Social da PUC-Rio como parte dos requisitos parciais para obtenção do título de Doutor em Serviço Social.

Orientadora: Ângela Maria de Randolpho Paiva 
Andréia Clapp Salvador

\title{
Ação Afirmativa no Ensino Superior: Estudo da Política de Inserção de Alunos Pobres e Negros na PUC-Rio
}

\begin{abstract}
Tese apresentada como requisito parcial para obtenção do grau de Doutor pelo Programa de Pós-Graduação em Serviço Social do Departamento de Serviço Social do Centro de Ciências Sociais da PUC-Rio. Aprovada pela Comissão Examinadora abaixo assinada.
\end{abstract}

Prof. ${ }^{a}$ Ângela Maria de Randolpho Paiva

Orientadora

Departamento de Sociologia e Política - PUC-Rio

Prof. ${ }^{a}$ Vera Maria Ferrão Candau Departamento de Educação - PUC-Rio

Prof. ${ }^{a}$ Denise Pini Rosalem da Fonseca Departamento de Serviço Social - PUC-Rio

Prof. ${ }^{a}$ Marlise Vinagre Silva Departamento de Serviço Social - UFRJ

Prof. ${ }^{a}$ Elielma Ayres Machado Departamento de Educação - UERJ

Prof. Nizar Messari Vice-Decano de Pós-Graduação do Centro de Ciências Sociais - PUC-Rio 
Todos os direitos reservados. É proibida a reprodução total ou parcial do trabalho sem autorização da universidade, da autora e da orientadora.

\section{Andréia Clapp Salvador}

Graduou-se em Serviço Social pela Pontifícia Universidade Católica do Rio de Janeiro (1988). Possui mestrado em Serviço Social pela Pontifícia Universidade Católica do Rio de Janeiro (1994). Atualmente, é professora auxiliar da Pontifícia Universidade Católica do Rio de Janeiro. Tem experiência na área de Serviço Social e está atuando principalmente nos seguintes temas: Ensino Superior, política afirmativa e desigualdades sociais.

Ficha Catalográfica

\section{Salvador, Andréia Clapp}

Ação afirmativa no ensino superior: estudo da política de inserção de alunos pobres e negros na PUC-Rio / Andréia Clapp Salvador ; orientadora: Ângela Maria de Randolpho Paiva. - 2008.

199 f. : il. ; $30 \mathrm{~cm}$

Tese (Doutorado em Serviço Social)-Pontifícia Universidade Católica do Rio de Janeiro, Rio de Janeiro, 2008. Inclui bibliografia

1. Serviço social - Teses. 2. Política de ação afirmativa. 3. Educação superior e pré-vestibular para negros e carentes. I. Paiva, Ângela Maria de Randolpho. II. Pontifícia Universidade Católica do Rio de Janeiro. Departamento de Serviço Social. III. Título. 


\section{Agradecimentos}

Esta tese é resultado de um trabalho coletivo. O caminho traçado teve a participação de muitas pessoas que contribuíram para sua realização. A todos e todas, o meu eterno reconhecimento.

Em especial, agradeço:

À PUC-Rio, pela bolsa de estudo que me foi concedida, sem a qual este trabalho não poderia ter sido realizado.

À minha orientadora, Ângela Maria de Randolpho Paiva, pelos momentos de orientação, dos quais pude desfrutar de sua reconhecida capacidade intelectual. Aqui fica minha gratidão por ter acreditado em mim.

À Vera Maria Ferrão Candau, co-orientadora, pela atenção que tive ao longo desses anos, pelo que aprendi e pelo exemplo que é na luta por um mundo mais justo.

À professora Maria Aparecida Barbosa Marques, a primeira orientadora da tese, pela sua capacidade de apostar no novo. Obrigada pela sua confiança.

Aos professores que me honraram, aceitando fazer parte da banca que analisará a presente tese.

Aos elaboradores e gestores, e a cada um dos alunos do programa de bolsa ação social da PUC-Rio. A minha gratidão mais profunda pelos belos depoimentos e pela confiança que depositaram em mim. Vocês são um exemplo de vida.

À equipe de profissionais e ex-alunos bolsistas de ação social da PUC-Rio, que me apoiaram durante o processo de construção desta tese. Ao Marcelo Prata, Assistente Social, pelo seu companheirismo e competência na pesquisa de campo. Ao Valmir Azevedo, professor de Língua Portuguesa e Literatura, pela eficiência 
e carinho que marcam seu trabalho de revisão. À Priscilla, futura professora de Letras, pelas transcrições tão bem organizadas, e à Eliza Batista, formada em Letras, pelo belo material gráfico.

Aos professores e funcionários do Departamento de Serviço Social pelo incentivo. Em especial à Marilene, à Joana e à equipe da secretaria. Meu muito obrigada.

Às minhas queridas Luiza Helena Nunes Ermel e Arlete Alves Lima. Um agradecimento especial.

À Patrícia Siciliano, Suely Martinho e equipe, Ricardo Courvisier e Eduardo Massad. A vocês, muito obrigada sempre.

Aos colegas da primeira turma e, especialmente, à Maria Helena Tavares, companheiros desta longa caminhada.

Aos meus familiares, pelo amor e apoio irrestrito; em especial a Roberto (in memoriam) e Daura, meus pais, que, sem eles, tudo seria impossível.

Principalmente a Deus, que me iluminou durante todo o desenvolvimento deste trabalho. 


\section{Resumo}

Salvador, Andréia Clapp; Paiva, Ângela Maria de Randolpho. Ação Afirmativa no Ensino Superior: Estudo da Política de Inserção de Alunos Pobres e Negros na PUC-Rio. Rio de Janeiro, 2008. 199p. Tese de Doutorado - Departamento de Serviço Social, Pontifícia Universidade Católica do Rio de Janeiro.

A presente tese, Ação Afirmativa no Ensino Superior: Estudo da Política de Inserção de Alunos Pobres e Negros na PUC-Rio, busca responder a algumas questões pertinentes ao programa de ação social desenvolvida na Pontifícia Universidade Católica do Rio de Janeiro. A PUC-Rio vem implementando uma política de ação afirmativa desde 1994, com o objetivo de favorecer o acesso de camadas populares da sociedade aos cursos de graduação, prioritariamente estudantes oriundos do Pré-Vestibular para Negros e Carentes. Este estudo, tendo como base a pesquisa de campo realizada nos anos de 2006 e 2007, procura compreender, especificamente, dois aspectos: a gênese do programa afirmativo e o impacto desse programa na vida dos alunos beneficiados. Com relação à gênese do programa, buscou identificar alguns dos principais implementadores e gestores do programa de ação afirmativa e, a partir daí, conhecer como se deu a formação desta política e os motivos que os levaram a participar de sua constituição. Com relação à vivência dos ex-alunos bolsistas de ação social, os beneficiários do programa afirmativo, procurou conhecer quais foram os principais impactos vividos por eles durante a vida acadêmica e depois de formados. A pesquisa qualitativa se apresentou como o melhor recurso metodológico para entender a complexidade desses dois momentos. Para a coleta de dados, utilizou-se a entrevista semi-estruturada, que se caracteriza por permitir que o entrevistado fale com liberdade sobre o assunto, sem perder o enfoque na temática proposta, conseguido com roteiros aplicados em todas as entrevistas. Foram utilizadas duas entrevistas: a primeira dirigida aos implementadores e elaboradores da política afirmativa e a outra aos ex-alunos do programa. Como resultado deste trabalho, é possível observar que a política afirmativa atingiu não só os alunos, suas famílias e comunidades, mas também vem contribuindo para a consolidação de um espaço universitário mais diverso, pois, com o nascimento do programa, ocorreu tanto a formação de uma nova composição do alunado como, também, o acesso ao 
Ensino Superior de alunos provenientes de classes populares, tornado, assim, o campus mais diversificado e mais democrático.

\section{Palavras-chave}

Política de ação afirmativa; Educação Superior; Pré-Vestibular para Negros e Carentes. 


\section{Abstract}

Salvador, Andréia Clapp; Paiva, Ângela Maria de Randolpho (Advisor). Affirmative action in higher education: A study of social inclusion policies for the black and poor students in Catholic University of Rio de Janeiro. Rio de Janeiro, 2008. 199p. PhD. Thesis - Departamento de Serviço Social, Pontifícia Universidade Católica do Rio de Janeiro.

Ação Afirmativa no Ensino Superior: Estudo da Política de Inserção de Alunos Pobres e Negros na PUC-Rio searches to answer some questions that arise from the discussion regarding the social action program developed in the Catholic University of Rio de Janeiro (PUC). PUC-Rio has been implementing a specific affirmative action politics since 1994 whose objective is to grant higher education access to popular social classes of society, especially students from the PréVestibulares para Negros e Carentes (PVNCs). By having a field research done in the years 2006 and 2007 as a basis, this study focuses on two aspects of the affirmative program: Its beginning - the characters responsible for its formulation, implementation and management-and its impact in the lives of the beneficiary students during and after undergraduation. Qualitative research was chosen as the best methodological resource in order to understand the complexity of those two moments. To collect data, semi-structured interview was applied, which allows interviewees to speak freely and focused on the proposed theme. Two different types of interview scripts were used: One specifically directed to the characters responsible for the implementation/collaborators of the affirmative politics, and the other to the former students of the program. As a result of this work, one can observe that the affirmative politics implemented in PUC-Rio influenced not only its beneficiary students, their families and communities, but it also has been contributing for the consolidation of a more diverse and democratic university environment and campus.

\section{Keywords}

Affirmative action policy; Higher Education; Pré-Vestibular para Negros e Carentes. 


\section{SUMÁRIO}

1. Introdução

2. Política de Ação Afirmativa - Uma Nova Perspectiva de Enfrentamento das Desigualdades Sociais

2.1. A questão da desigualdade social no Brasil - Algumas considerações

2.2. A desigualdade racial no Brasil

2.3. Políticas de reconhecimento $X$ políticas de redistribuição Um dilema contemporâneo

2.3.1. Entre a política de reconhecimento e a política de redistribuição - Existe um modelo ideal de política? Um primeiro dilema

2.3.2. A questão da igualdade e da diversidade nas políticas de reconhecimento e políticas de redistribuição - Um segundo dilema

3. Política de Ação Afirmativa no Brasil - Uma Questão Contemporânea

3.1. Política de ação afirmativa - Algumas considerações sobre a questão

3.2. A influência americana no modelo brasileiro

3.3. Por que políticas de ação afirmativa?

3.4. As políticas de ação afirmativa - Uma experiência brasileira

4. A Gênese da Política de Ação Afirmativa da PUC-Rio - Uma

Parceria entre Universidade e Movimento Social

4.1. A atuação dos novos movimentos sociais

4.2. O Pré-Vestibular de Negros e Carentes - Uma experiência dos novos movimentos sociais

4.3. Política de ação afirmativa - A experiência da Pontifícia

Universidade Católica do Rio de Janeiro 
4.4. A gênese da Política de ação afirmativa da PUC-Rio - Uma experiência contada pelos seus implementadores

4.4.1. A firmação de um programa

4.4.1.1. A influência dos movimentos sociais católicos na concepção da política afirmativa da PUC-Rio

4.4.2. Alguns importantes atores e suas principais motivações

4.5. O processo de consolidação de uma política afirmativa

4.5.1. Novos parceiros e novas parcerias

5. O Impacto da Ação Afirmativa na Vida dos Estudantes Universitários

5.1. A questão da alteridade

5.2. O impacto e o alcance da ação afirmativa na vida dos estudantes - A trajetória dos alunos bolsistas de ação social da

PUC-Rio

5.2.1. O perfil dos alunos entrevistados

5.2.2. Um primeiro momento: o começo da vida acadêmica

125

5.2.3. Um segundo momento: vivência do aluno bolsista de ação social em sua trajetória universitária

5.2.4. Um terceiro momento: a vida do aluno depois da formatura

157

6. Considerações finais

7. Referências bibliográficas

Apêndice B

Apêndice C

Apêndice D 